\title{
RESEARCH ON TORQUE COMPENSATION WITH OPTIMAL PEDAL THROTTLE FOR DIRECT-DRIVE ELECTRIC VEHICLE START-UP
}

\author{
Ping Xiong, Chenglin Gu
}

Original scientific paper

The original rigid connection between the motor and the hub is replaced with a flexible one using the clutch to connect the driving and driven sides of the driveline system. Then the paper proposes a separable process of motor start-up and load operation, based on which the scheme of idle speed control is studied. Focusing on the contradiction between the extended torque capacity and the reduced vehicle jerk merely by tuning the idle speeds, an improved solution is proposed for toque compensation by throttle adjustment during the clutch engagement. Furthermore, the method for tracking the armature voltage of the driving motor is investigated and optimized, aiming at the balance between the demanded transmitted torque and the jerk level during the starting process. Finally, effectively enhanced torque capacity of the driving motor for the vehicle start-up on the premise of the improved comfort level has been demonstrated by experiments.

Keywords: armature voltage compensation; direct-drive; flexible coupling; idle speed; vehicle jerk

\section{Istraživanje kompenzacije zakretnog momenta s optimalnom prigušnicom pedale za pokretanje električnog vozila izravnog stupnja prijenosa}

Izvorni znanstveni članak

Originalna kruta veza između motora i glavine zamijenjena je fleksibilnom uporabom spojke za povezivanje pogonskog i gonjenog vratila sustava prijenosa. U radu se zatim predstavlja odvojeni proces pokretanja i opterećenja motora na osnovu kojega se analizira shema reguliranja rada motora u praznom hodu. Fokusiranjem na probleme koordinacije povećanog kapaciteta zakretnog momenta i smanjenja trzaja automobila samo regulacijom rada motora u praznom hodu, predlaže se poboljšano rješenje kompenzacije zakretnog momenta podešavanjem napona rotora dok se spojka aktivira gonjenom stranom. Nadalje, ispituje se i optimizira metoda za označavanje napona zakretnog momenta s ciljem stvaranja balansa između traženog prijenosnog mehanizma zakretnog momenta i jačine trzaja tijekom pokretanja vozila. Konačno, eksperimentima je demonstriran učinkovito poboljšani učinak zakretnog momenta pogonskog motora kod pokretanja vozila u svrhu povećane udobnosti.

Ključne riječi: elastična spojka; izravni prijenos; kompenzacija napona rotora; rad motora u praznom hodu; trzaj vozila

\section{Introduction}

Direct-drive electric vehicles (EVs) are gaining momentum in the automotive industry due to their interesting combination of properties such as the lightness, higher efficiency, no gearboxes or differentials and an independently control mode [1]. Thus it gives far greater flexibility to vehicle designers while substantially reducing drivetrain losses. Considering the driving torque needs to be reacted between the vehicle suspension knuckle and the wheel-hub, these two components are usually rigidly connected by mechanical components like wheel bearings. The additional resistance torque caused by the static friction in between these components is thereby unavoidable when the vehicle accelerates from a standing start [2]. Therefore, the prolonged time of the electromagnetic shock to the armature winding of the driving motor and the vehicle battery are suffered particularly under such starting circumstances. Also, the voltage surge could be arisen because of the higher $\mathrm{d} i / \mathrm{d} t$, when the EV brakes at a high speed or switches off its power at a higher load current. It may cause potential harm to the components such as the Hall sensors or the controllers [3].

Like traditional cars, in which a mechanical friction clutch is used to make the smooth torque transfer within vehicle starting and gear shifting [4]. Besides, some decrease in the residence time of the electromagnetic shock becomes possible when a centrifugal clutch is applied to assist with motor starting under load [5]. In addition to that, the sudden voltage spike seen across an inductive load when its supply voltage is suddenly reduced or removed will be possibly eliminated by the implementation of 'detached braking' (the driving motor is disengaged from the vehicle load and its rotor spins freely until friction slows it to a stop). Also, with the inclusion of clutch within a vehicle, a reduction in coasting loss can be realized by disengaging the driving motor from the vehicle load [6].

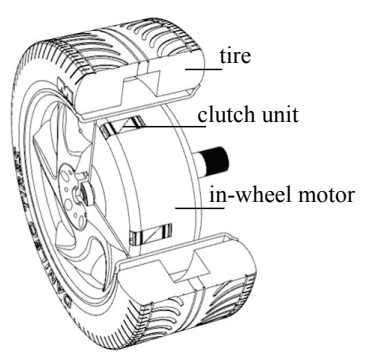

(a)

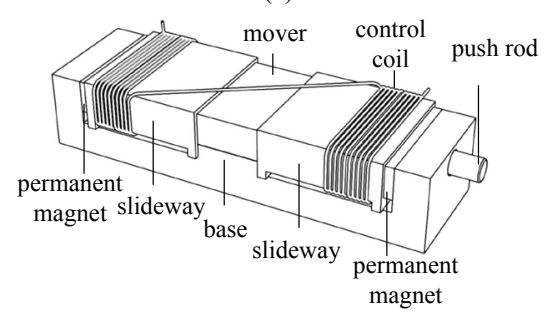

(b)

Figure 1 One demonstration of the integration design for the assembly of the new-type clutch in in-wheel drive system: (a) schematic diagram of the assembly of the new type clutch units between the hub and the motor for an in-wheel drive system, (b) new type clutch unit

Therefore, like utilizing clutch mechanism to reduce the electromagnetic and mechanical shocks, a novel 
clutch is introduced into the driveline of the direct-drive propulsion system for the purpose of achieving a flexible connection between the motor and the hub. In order to retain the distinguishing merits such as a compact powertrain and the independent control for each wheel motor, the new-type clutch is designed and its working principle is illustrated in [7]. The existing features (e.g. flat structure, flexible control and energy-saving) make it more suitable to be applied for the in-wheel drive application. Accordingly, the proposed concept for the flexible connection between the motor and the hub is realized and demonstrated in Fig. 1. Composed of several clutch units that are placed on the outer surface of wheelrotor, the actuator operates like a dog clutch for the power transfer and interruption between the driving (the motor) and driven sides (the load) of the in-wheel electric drive system.

Generally, clutch engagements without throttle are recommended for diesel engines, but the restricted starting torque may lead to the stall of engine or start-up failure during cases where the additional driving resistance arisen from road roughness or wheel sinkage needs to be overcome for propelling the vehicle into motion. Increasing the fly-wheel kinetic energy of the driving side is advantageous to the vehicle starting. For example, in the case of conditions where a larger driving torque is required to overcome the additional starting resistance moment, an operation of sudden clutch engagement is utilized for the vehicle start-up while the engine is coupled to the wheel at a high speed difference [8]. But it brings obvious shock and lowers the comfort level, although propelling the vehicle from a standing start. Conflictive objectives between the start-up jerk and the demanded driving torque for assuring the smaller discontinuity in the acceleration of the driven side may not well balanced only by the clutch start mode with an inappropriate speed difference between the driving and driven sides of the driveline system.

Starting a vehicle with the use of a throttle is commonly exercised in vehicles within gasoline engines. And any vehicle starts that use a throttle depend, more so than those without throttle, on subjective human interventions. Uncomfortable feelings will be equally experienced by drivers and passengers when applying a rapid tip-in on the accelerator pedal without considering the actual load conditions [9].

Thus, a method using automatic voltage adjustment of driving motor during the clutch engagement is proposed, which is the supplement for the clutch start mode merely relying on the adjustment of idle speed in previous work [10]. Without considering the driver's intention, the track of armature voltage of the driving motor is automatically adjusted to produce a required torque and a smooth engagement at the time of clutch closure while the clutch is being engaged to the driven side. Correspondingly, the study on the different terminal voltage is optimized based on the requirement of the load torque in this paper.

\section{Components modelling of the driveline of direct-drive electric vehicle system}

The driveline of the direct-drive EV drive system proposed in this paper consists of three parts, e.g. the driving motor, the coupling mechanism, and the vehicle resistance. Before analyzing and developing the corresponding idle speed control with or without armature voltage compensation, following assumptions are made for simplicity. Ignoring the influence of the wheel slip, the vehicle mass is lumped together into a separate inertia referred to the rotational shaft of the driving motor.

\subsection{Driving motor modelling}

For simplifying control strategy of the driving motor and focusing on the investigation of the scheme of torque compensation based on the idle speed control, therefore, a DC motor is selected as the power source of the entire driveline system. The mathematical model of the DC motor can be described by the following electrical and mechanical equations:

$$
\begin{aligned}
& L_{\mathrm{a}} \frac{\mathrm{d} i}{\mathrm{~d} t}+i r_{\mathrm{a}}+E=u \\
& J_{\mathrm{m}} \frac{\mathrm{d} \omega}{\mathrm{d} t}=T_{\mathrm{e}}-T_{\mathrm{L}}
\end{aligned}
$$

where $i$ is the armature current, $\omega$ is the mechanical angular velocity, $r_{\mathrm{a}}$ and $L_{\mathrm{a}}$ are the armature resistance and the armature inductance respectively, $u$ is the armature voltage, which is controlled by accelerator pedal, $J_{\mathrm{m}}$ is the moment of inertia of the driving motor, $T_{\mathrm{L}}$ is the load torque, $T_{\mathrm{e}}$ is the driving torque from the DC motor, and $E$ is the back emf (electromotive force), which is presented as:

$$
E=K_{\mathrm{e}} \cdot \omega
$$

where $K_{\mathrm{e}}$ is the emf constant of the DC motor.

\subsection{Vehicle resistance modelling}

The driving resistance of the vehicle mainly contains four parts: rolling friction, aerodynamic drag, grade force and inertial resistance. Aerodynamic drag force is small enough to be ignored when the vehicle is launched from standstill, compared with other factors like the rolling resistance and the hill climbing force at the initial time of start-up. Additionally, the vehicle mass is lumped into an equivalent inertia referred to the rotational shaft of driving motor, and is then given by:

$$
J_{\mathrm{v}}=M_{\mathrm{v}} R_{\mathrm{w}}^{2} / G
$$

where $M_{\mathrm{v}}$ is the total mass of the EV including the load, $R_{\mathrm{w}}$ is the tire radius of the $\mathrm{EV}$, and $G$ is the gear ratio, which is one in direct-drive EV.

Thus the vehicle resistance can be modeled by:

$$
F=F_{\mathrm{i}}+F_{\mathrm{r}}=M_{\mathrm{v}} g \sin \varphi+\mu_{\mathrm{r}} M_{\mathrm{v}} g
$$

where $\mu_{\mathrm{r}}$ is the coefficient of rolling resistance, $g$ is the acceleration of gravity, $\varphi$ is the grade angle, $F_{\mathrm{i}}$ is the grade resistance, and $F_{\mathrm{r}}$ is the rolling resistance. Correspondingly, the resultant force $F$ will produce a 
resistance torque $T_{\mathrm{L}}$ to the driving motor, the relation of which is given by the following equation:

$$
T_{\mathrm{L}}=F \frac{R_{\mathrm{w}}}{G}
$$

In general, the rolling loss group includes friction losses in wheel bearings, transmission components, and hysteretic loss of the tyre-road interface. It is indicated that rolling friction was increased by flange contact and by sand or leather on surfaces. Additionally, the road roughness would raise static resistive force, while having a non-obvious influence on kinetic resistance [11]. Based on the variation law of the coefficient of bearing friction, in which the dynamic coefficient keeps a relatively small value when the vehicle travels at a high speed, whereas a higher coefficient or traction load is obtained at a low speed. In this case, the static frictional resistance like the bearing drag needs to be taken into consideration, in particular during the frequent starting and stopping conditions [12]. It is concluded that the tractive force that is required to set the vehicle into motion would reach several times as much as the resistive force acting on wheel at steady state condition, as the result of frictional behavior of the contact surfaces or the strong action between the wheel and the terrain [13].

Accordingly, by taking into consideration the multiple factor above-mentioned, the symbol $\mu_{\mathrm{s}}$ is used to represent the static coefficient of rolling resistance, while the $\mu_{\mathrm{r}}$ stands for the dynamic coefficient when the vehicle is set into motion [14].

\subsection{Clutch engagement modelling}

The initial kinetic energy of the flywheel mounted on the driving side of the driveline system is used to set the vehicle into motion from rest before the clutch is engaged to the driven side. Owing to the speed difference between driving and driven sides while clutch is engaging, the engagement process of the two sides is described by two different phases, which are defined as the synchronizing and engaged phases respectively. The dynamic equations of clutch engagement at the synchronizing phase can be presented as:

$$
\begin{aligned}
& J_{\mathrm{m}} \dot{\omega}_{\mathrm{e}}=T_{\mathrm{e}}-T_{\mathrm{c}} \\
& J_{\mathrm{v}} \dot{\omega}_{\mathrm{v}}=T_{\mathrm{c}}-T_{\mathrm{L}}
\end{aligned}
$$

where $T_{\mathrm{c}}$ is the clutch torque, $\omega_{\mathrm{v}}$ is the angular speed of the load, and $\omega_{\mathrm{e}}$ is the angular speed of the DC motor.

Acted upon by the equivalent clutch torque $T_{\mathrm{c}}$, the speed of the driving motor is reduced while the load speed is increased during the synchronizing phase. The clutch is fully engaged once the speed difference between the driving and driven sides is close to zero during the synchronizing phase. Then the time $\left(t_{\mathrm{c}}\right)$ required for the clutch engagement can be calculated by:

$$
t_{\mathrm{c}}=\frac{\omega_{0} J_{\mathrm{m}} J_{\mathrm{v}}}{J_{\mathrm{v}}\left(T_{\mathrm{c}}-T_{\mathrm{e}}\right)+J_{\mathrm{m}}\left(T_{\mathrm{c}}-T_{\mathrm{L}}\right)}
$$

$\omega_{0}$ is the zero-load angular speed of the driving motor, called the idle speed, at which the driving motor is idling before the driving side is coupled to the driven side of the driveline system.

Due to the rapid clutch engagement at a higher speed difference between the driving and driven sides, there is a transfer of angular momentum from the driving side to the driven side. The action of quick clutch engagement always produces high driveline loads for short duration in the engine mounts and driveline components [15]. As a result, assuming the equivalent clutch torque is far greater than the motor torque and the load torque, the final angular speed of the load can be simplified by:

$t_{\mathrm{c}} \frac{T_{\mathrm{c}}}{J_{\mathrm{v}}}=\frac{\omega_{0} J_{\mathrm{m}}}{J_{\mathrm{m}}+J_{\mathrm{v}}}$

The left side of Eq. (10) represents the angular speed change of the load when the clutch is completely closed, and it is simply influenced by the no-load angular speed while the driving motor is idling.

Further, the ideal mechanical coupling between two rotating masses with different speeds instantly engages and disengages. In a closed state, there is a fastened connection between the driving and driven sides, and in an open state, the clutch does not transmit any force or torque. Hence, this paper treats such an event of the friction or the dog clutch coupling as a completely inelastic collision and calculates the collision speed on the basis of angular momentum conservation law [16, 17]. The angular speed of the load is governed by:

$$
J_{\mathrm{m}} \omega_{0}=\left(J_{\mathrm{m}}+J_{\mathrm{v}}\right) \omega_{1}
$$

$\omega_{1}$ is the common angular speed when clutch is closed. Once the speed difference between the driving and driven sides has been close to zero, and then the wheel load is flexibly coupled to the driving motor, behaving like a linked part. The single-DOF (degree of freedom) dynamic model of the clutch at the engaged phase is presented as:

$$
T_{\mathrm{e}}-T_{\mathrm{L}}=\left(J_{\mathrm{m}}+J_{\mathrm{v}}\right) \frac{\mathrm{d} \omega}{\mathrm{d} t}
$$

The results of Eq. (10) and Eq. (11) show that the common angular speed after the sudden engagement of the clutch in the motor-clutch-load system is equal to collision speed by the ideal mechanical coupling. The initial speeds are obtained by both drive and driven sides after the rapid clutch engagement. In contrast with vehicle start-up from standstill, the increase of the wheel speed will help to reduce free rolling resistance force and wheel sinkage, in turn, the demanded driving torque for vehicle start-up will be decreased to some extent [18].

\section{Design of scheme for the improved torque capacity based on idle speed control}

\subsection{Evaluation indicators of start-up performance}

Vehicle drivability is an important aspect for reflecting the driving smoothness of vehicle start-up and 
comfort level of gear shifting. However, it is susceptible to driver's subjective perception. Previous researches have concluded that peak-to-peak acceleration and jerk (change rate of acceleration) are the key factors that assess the impact on the shifting quality or drivability performance [19]. Ignoring vertical and horizontal vibrations, most of researches at present quantifies the performance of vehicle start-up or shifting process objectively by measuring the change rate of longitudinal acceleration of the vehicle $(\dot{a})$, the so-called jerk, which accounts for the phenomenon of wearing 'head nod' effect on passengers during gear shifting or sudden vehicle starting. Besides, the peak armature current is considered as a performance index for the reflection of electromagnetic impulsion.

\subsection{Implementation of idle speed control with armature voltage adjustment \\ 3.2.1 Control flowchart of the proposed method}

In practical applications, the resistance force at the initial time of start-up can be approximately obtained from the sensors or the initial displacement of brake pedal when the vehicle is launched on a slope from standstill. Additionally, GPS signals and grade sensors are equipped in some modern trucks and can be used to obtain the grade angle. This practice can enhance the estimation accuracy of starting resistance force [20]. Consequently, a closed-form expression of control strategy with load feedback for the separable starting process of motor and load operations becomes possible.

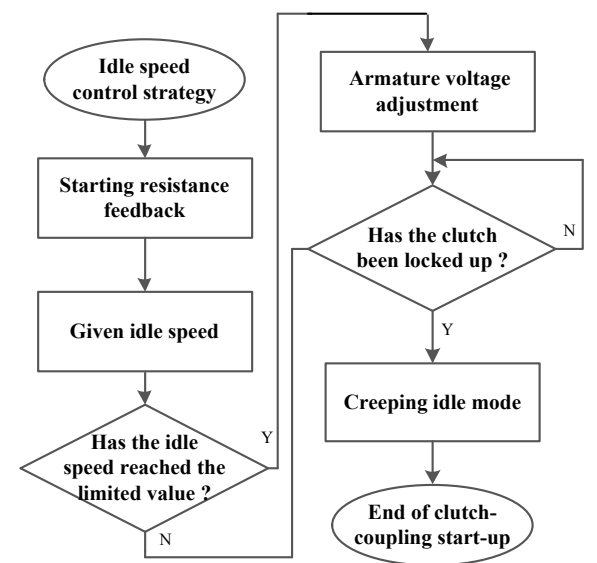

Figure 2 Flowchart of the idle speed control strategy with armature voltage adjustment

The specific flowchart of the variable-idle speed control is shown in Fig. 2. The initial speed when the clutch begins to be engaged to the driven side is given based on the fitted curves between the idle speed and the starting resistance force, and the relationship between them was investigated and optimized in [10]. Due to the limitation of the load capability, the negative acceleration of the load could potentially occur after clutch engagement at a fixed idle speed. Thus the variable-idle speed control scheme is proposed for compromising the driving comfort and the improvement of torque capacity. But, the main cause of uncomfortable jerk is the rapid clutch engagement at a high relative angular velocity between the driving and driven sides for satisfying the requirement of the load torque [21]. Therefore, the rotational speed to be engaged to the driven side should be necessarily limited to a certain range.

In order to keep a balance between the preservation of the driving comfort and further improvement of transmitted torque capacity, the armature voltage of the driving motor is adjusted when the idle speed reach its upper limit value. Then the compensation scheme concerning the track of the armature voltage for enhancing torque capacity is executed on the condition that the deceleration of the load is arisen after clutch is locked, even though the restricted idle speed being engaged to the driven side.

Considering the specific strategy for the accelerating stage is not the focus of the paper, the armature voltage that corresponds to the given idle speed stays constant for keeping the load running at a creeping speed after the clutch engagement in this article. In fact, optimal energy dissipation of DC traction motor during the accelerating phase is extensively investigated. Optimal track of armature voltage of the DC motor after clutch engagement for the energy-efficient drive can be achieved by implementing the proposed strategy in [22].

\subsubsection{Influence of the idle speed on the start-up performance indices}

As mentioned above, the action of rapid clutch engagement during the synchronizing phase complies with ideal clutching process, and thereby theorem of impulse is applied to the driveline system. Accordingly, the equivalent angular acceleration of the load is given by:

$$
\frac{\Delta \omega}{\Delta t}=\frac{\bar{T}}{J_{\mathrm{v}}}
$$

where $\bar{T}$ is the equivalent average torque, $\Delta t$ is the engagement time, and $\Delta \omega$ is the change of angular velocity. The jerk level is calculated by the defined equation:

$$
\dot{a}=\frac{\mathrm{d} a}{\mathrm{~d} t}
$$

where $a$ is the longitudinal acceleration.

Due to the fact that a very fixed step for numerical simulation is generally less than $1 \mathrm{~ms}$, direct calculation of jerk level by Eq. (14) would bring high frequency contents. Further, relevant investigations have found that human beings are more sensitive to the oscillations ranged between $10 \mathrm{~Hz} \sim 14 \mathrm{~Hz}$ while insensitive to longitudinal shocks above $50 \mathrm{~Hz}[19,23]$. For this reason, the average jerk is defined for the evaluation of the shock intensity with the sampling frequency of $100 \mathrm{~Hz}$.

Combining Eq. (11), Eq. (13) and Eq. (14), the average jerk value for quantifying comfort level while clutch begins to be engaged to the driven side should be satisfied by:

$|\dot{a}|=\frac{J_{\mathrm{m}}}{J_{\mathrm{m}}+J_{\mathrm{v}}} \frac{R_{\mathrm{w}} \omega_{0}}{\Delta t \cdot T_{\mathrm{s}}} \leq$ Const 
where $T_{\mathrm{s}}$ the sampling period, Const is a positive constant to be chosen, the value of which is $10 \mathrm{~m} / \mathrm{s}^{3}$ in German standard and $17 \mathrm{~m} / \mathrm{s}^{3}$ in China standard [24].

The transmitted torque at the clutch closure time $\bar{t}$ is governed by the electrical and mechanical equations of the DC motor. The DC motor remains steady state before the clutch is released, then the ideal zero-load angular speed is determined by:

$$
\omega_{0}=\frac{u}{K_{\mathrm{e}}}
$$

Since the rapid clutch engagement can be regarded as the ideal clutch model, the process of which can be treated as a completely inelastic collision. The angular speed of the driving motor is linearly dropped under the equivalent average torque while the clutch is synchronizing, so the Eq. (7) is simplified by:

$$
-T_{\mathrm{c}}=J_{\mathrm{m}} \frac{\mathrm{d} \omega_{\mathrm{e}}}{\mathrm{d} t}
$$

Meanwhile, the armature current is increased from the ideal no-load current to the expected load current $i_{\mathrm{L}}$. Then the analytical solution of armature current response can be calculated by the solution of Eq. (1), Eq. (11) and Eq. (17):

$$
\left\{\begin{array}{l}
i(t)=r_{\mathrm{a}}^{-1}\left[\mathrm{~A} t+\left(\mathrm{B}-\mathrm{A} \tau_{a}\right)\left(1-\exp \left(-\frac{t}{\tau_{a}}\right)\right)\right] \\
\mathrm{A}=K_{\mathrm{e}} \frac{\omega_{0}-\omega_{1}}{\Delta t}, \mathrm{~B}=u-K_{\mathrm{e}} \omega_{0}
\end{array}\right.
$$

where $\tau_{\mathrm{a}}$ is the electromagnetic time constant. Ignoring the effects of armature reaction, the per-unit value of transmitted torque during clutch engagement is equal to the one of armature current. It shows from Eq. (18) that the transmitted torque at clutch closure time can be directly adjusted through the idle speed if the engagement time duration $\Delta t$ is determined.

\subsubsection{Control objectives}

The motor torque is transmitted through the powertrain to the wheel load directly after the clutch is closed, while the clutch torque during the synchronizing phase. The discontinuity of the vehicle acceleration may be caused at the clutch closure time if the idle speed will not suitably be chosen. The inappropriate mismatch speed between the driving and driven sides can also lead to uncomfortable feelings to drivers when the clutch begins to be engaged, although the higher driving torque is obtained after the clutch is completely closed. It is therefore necessary to assure a smaller variation of the load acceleration before and after the speed synchronization of the driving and driven sides. The implementation of armature voltage compensation base on the idle speed control is performed according to the actual load condition for satisfying the following objectives:
- $\quad$ enhancing the torque capacity of the driving motor without inducing additional jerk level

- ensuring the continuity of angular acceleration of the load at the clutch closure time instant $\bar{t}$.

\subsubsection{Track of the armature voltage compensation based on idle speed control}

Apparently, the performance indices, described in Eq (15) and Eq. (18), are directly influenced by the idle speed. Increasing the idle speed will result in larger transmitted torque and jerk value and vice versa. The control objective, therefore, is to seek a compromise between the driving comfort and the requirement of transmitted torque for wheel load by adjusting the idle speed.

The discontinuity of the acceleration of the load at the clutch closure time $\bar{t}$ is proportional to the slip acceleration just before the clutch is closed [25], and is derived by:

$$
\left\{\begin{array}{l}
\dot{\omega}_{\mathrm{v}}\left(\bar{t}^{+}\right)-\dot{\omega}_{\mathrm{v}}\left(\bar{t}^{-}\right)=\frac{J_{\mathrm{m}}}{J_{\mathrm{m}}+J_{\mathrm{v}}} \dot{\omega}_{\mathrm{sl}}\left(\bar{t}^{-}\right) \\
\dot{\omega}_{\mathrm{sl}}\left(\bar{t}^{-}\right)=\dot{\omega}_{\mathrm{e}}\left(\bar{t}^{-}\right)-\dot{\omega}_{\mathrm{v}}\left(\bar{t}^{-}\right)
\end{array}\right.
$$

$\dot{\omega}_{\mathrm{sl}}$ represents the slip angular acceleration, $\dot{\omega}_{\mathrm{v}}\left(\bar{t}^{+}\right)$and $\dot{\omega}_{\mathrm{v}}\left(\bar{t}^{-}\right)$denote accelerations of the load at the instant of post-synchronization and pre-synchronization respectively. $\omega_{\mathrm{e}}\left(\bar{t}^{-}\right)$stands for angular speed of the driving motor just before clutch closure. During rapid clutch engagement, considering the variation of angular speed of the driving motor is far larger than one of the load at the same time interval, the discontinuity of the angular acceleration of the load at clutch closure time can be equally converted into the angular speed variation of the driving motor at the starting moment. Combining the Eq. (15) and Eq. (19), the engaging speed should be restricted to a certain range for assuring both the degree of the jerk when the clutch begins to be engaged to the driven side and the discontinuity in the acceleration of the load at the clutch closure time:

$$
\omega_{0} \in\left[0, \omega_{\max }\right]
$$

$\omega_{\max }$ can be calculated from Eq. (15) and represents the upper limit of the idle speed for ensuring the jerk level is below the recommended driving comfort. Meanwhile, the enough transmitted torque for avoiding the negative acceleration of the load should be promised at the instant time when clutch is fully engaged:

$$
T_{\mathrm{e}}\left(\bar{t}^{+}\right) \geq T_{\mathrm{L}}
$$

In case the transmitted torque is included into the optimization, a whole set of solutions results, according to different idle speeds. The idle speed is preferred for nonnegative load acceleration when the clutch is completely closed on the premise of driver's comfort, which will result in both the decrease of peak current. Accordingly, in contrast with the start-up process at the fixed idle speed, 
torque capacity is apparently extended when the idle speed is adjusted within the maximum idle speed $\left[0, \omega_{\max }\right]$ for the vehicle start-up.

Further, in order to guarantee the transient jerk that will be below the recommended jerk value while the clutch begins to be engaged to the driven side, the idle speed should be limited to a certain range, which leads to the restriction of torque capacity. It may cause slip slope or startup failure only by tuning the idle speeds for vehicle launch under difficult road conditions, in which the increase of driving force is due to the wheel sinkage or road roughness, etc. Thus, the track of the armature voltage is adjusted to assure the enough transmitted torque after clutch engagement for the purpose of preventing vehicle running backward. Accordingly, the given terminal value of the armature voltage $U_{\mathrm{g}}$ is adjusted within the certain range governed by the following expression:

$$
u \in\left[U_{\min }, U_{\max }\right]
$$

where $U_{\min }$ denotes the armature voltage corresponding to the upper limit of the idle speed, $U_{\max }$ represents the rated voltage of the driving motor. Subjected to the adjustment of the armature voltage during the synchronizing phase, the analytical solution of armature current response is determined by following equation:

$$
L_{\mathrm{a}} \frac{\mathrm{d} i}{\mathrm{~d} t}+i r_{\mathrm{a}}=F(t)
$$

where $F(t)$ indicates the function of voltage variation with time. Theoretically, the expected track of the armature current can be regulated by controlling the track of the armature voltage during synchronizing phase. Aiming at the adjustment of terminal value of the armature voltage $U_{\mathrm{g}}$, the simplified trajectory curve of the armature voltage is considered, the track of which with time is linearly risen to the given terminal value of the armature voltage from initial given value of $U_{\min }$ :

$$
u(t)=\frac{U_{\mathrm{g}}-U_{\min }}{\Delta t} t
$$

Given that sudden engagement of the clutch, the adjustment of the armature voltage is considered as a step change during the synchronizing phase. Accordingly, the analytical solution of the armature current response during the synchronizing phase is same with Eq. (18).

For a better understanding of the adjustable variable $U_{\mathrm{g}}$, two performance indices, with respect to the jerk level and the starting current, are previously introduced that quantify, respectively, the comfort level and the electromagnetic impulsion.

When implementing the scheme of idle speed with the armature voltage adjustment for torque compensation, the enhancement of the driving torque at the clutch closure time is directly increased with $U_{\mathrm{g}}$, while the equivalent acceleration of the load is acquired when the clutch is engaged under the upper limit of the idle speed for preserving the comfort level.
Suppose $a\left(t_{0}\right)$ is equivalent load acceleration in time interval $\left[t_{0}, t_{1}\right]$ during the synchronizing phase, and $a\left(t_{1}\right)$ is in phase of the clutch closure and driving with the locked clutch for $t>t_{1}$, accordingly, $t_{0}$ denotes the time instant when the driving side begins to be engaged to the driven side, whereas $t_{1}$ is the closure time of clutch engagement.

When the $a\left(t_{1}\right)<0$, regarding the negative acceleration of the load occurs after the clutch is closed, it will result in $\left|a\left(t_{1}\right)-a\left(t_{0}\right)\right|>a\left(t_{0}\right)$. On the contrary, the expression $\left|a\left(t_{1}\right)-a\left(t_{0}\right)\right|<a\left(t_{0}\right)$ will be derived when the load acceleration at the clutch closure time is just passing through the boundary for the positive acceleration, i.e., $\left(a\left(t_{1}\right)>0\right)$. But, for the same time interval, the jerk value is equivalent to the discontinuity in the load acceleration, which is determined by the value of $\max \left(a\left(t_{0}\right)\right.$, $\left.\left|a\left(t_{1}\right)-a\left(t_{0}\right)\right|\right)$. Taking the driving comfort and the electromagnetic impulsion into account, the lower starting current and the smaller jerk value are usually preferred during the starting process. It implicitly indicates that there are any more improvements for the driving comfort with the increase of the peak current when the transmitted torque at the time of clutch closure is larger than the load torque.

The best possible, i.e. Pareto-optimal solutions of this multi-objective optimization, as concerning the transmitted torque at the clutch closure time and the peak jerk value, are defining the Pareto Front [26]. For solutions along the Pareto Front, no additional improvements to the jerk level in any case would result in an increase of the starting current. Therefore, the optimized terminal value of the armature voltage $U_{\mathrm{g}}$, which is obtained once the transmitted torque after clutch engagement is equal to the load torque, is regarded as the Pareto-optimal. Only one load condition is discussed at present, therefore, the result of optimization for the terminal value of the armature voltage $U_{\mathrm{g}}$ is regarded as the Pareto-optimal point.

\section{Experimental verification and results analysis}

To validate the effectiveness of the proposed control strategy for the improvement of the torque capacity of the driving motor without bringing additional jerk level, as well as the optimal armature voltage adjustment to find a compromise between the jerk level and the starting current, the test rig as shown in Fig. 3 is built for experimental research.

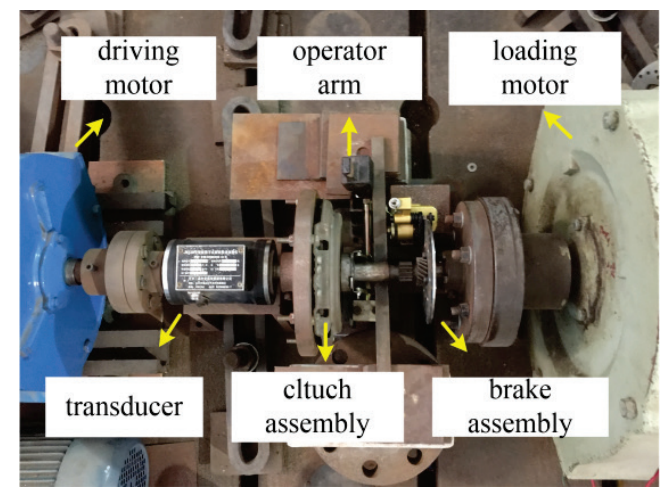

Figure 3 Test rig for simulating starting process of the load in directdrive mode with or without clutch coupling 


\subsection{Test rig}

The test rig mainly consists of following parts including the driving motor, the clutch assembly, the operator arm, brake assembly and the loading motor. A separately excited DC motor is chosen as the power source of the test rig, and the parameters of which are listed in Table 1.

The power is directly transmitted to the driven side of the driveline system when the clutch stays in a closed state, and the direct starting process under the rigid connection between the driving and driven sides is then realized on the test rig. Moreover, the experiments on achieving the separable process of the load and motor operations can be done by releasing the clutch operator until the flywheel mounted on the driving side speeds up to the expected zero-load speed. The impulse loads for a short duration in the driveline mounts can be produced by utilizing the kinetic energy induced by the fast movement of the pressure plate which is suddenly engaged to the rotating flywheel during clutch engagement process. So the rapid engagement of friction clutch on the test setup is capable of applying an 'impulse torque' directly to the driven side, similar to the instantaneous engaging process of an ideal clutch model to the greatest extent possible. So, the utilization of the friction clutch and its actuator for the separable starting process of the motor and load operations has no difference on the following experiments of the idle speed control with or without voltage adjustment.

Table 1 Parameters of the separated-excited DC motor

\begin{tabular}{|c|c|}
\hline Motor & Value \\
\hline$U_{\mathrm{N}}(\mathrm{V})$ & 110 \\
\hline$I_{\mathrm{N}}(\mathrm{A})$ & 35 \\
\hline$n_{\mathrm{N}}(\mathrm{r} / \mathrm{min})$ & 750 \\
\hline$r_{\mathrm{a}}(\Omega)$ & 0,512 \\
\hline$U_{\mathrm{f}}(\mathrm{V})$ & 220 \\
\hline$I_{\mathrm{f}}(\mathrm{A})$ & 1,36 \\
\hline$J_{\mathrm{m}}\left(\mathrm{kg} \cdot \mathrm{m}^{2}\right)$ & 0,4 \\
\hline
\end{tabular}

Additionally, the loading motor is located on the driven side and is used to mimic the steady load torque and the reference inertia of the vehicle. The steady and dynamic loading can be controlled through regulating the external resistor in series with armature resistance of the loading motor and the frictional force of the brake assembly respectively. The angular speed of the driving side and the load torque are measured by transducer installed among the powertrain system.

\subsection{Experiments and comparisons}

In the following, some contrast results achieved by applying the separable process of the motor starting and the load operation with or without voltage adjustment on the test rig are presented.

The induced armature voltage per unit speed can be obtained by the least squares curve fitting of experimental data. So the load speed can be estimated by measuring the armature voltage of the loading motor. The max reference value of armature voltage is limited to a value of $60 \mathrm{~V}$ and the load acceleration is estimated from the sampled load speed signal, using a differentiator in series with a firstorder low-pass filter and a rate limiter. The cut-off frequency of the filter has a value of $100 \mathrm{~Hz}$, which makes a good trade-off between noise and phase lag. The base values of the armature current and shock intensity are the rated current $(35 \mathrm{~A})$ and the recommended jerk value $\left(10 \mathrm{~m} / \mathrm{s}^{3}\right)$. The equivalent jerk $\dot{a}_{\mathrm{d}}$, which is computed by the second derivative of the sampled speed, is considered for the transverse comparisons of the jerk level between the clutch start mode with or without armature voltage adjustment in the following experiments.

Firstly, the clutch start-up is performed under the steady-load torque about $6 \mathrm{~N} \cdot \mathrm{m}$. The corresponding curves of the armature current, the load speed and the equivalent jerk while the clutch is engaged to the driven side at the speed of $50 \mathrm{r} / \mathrm{min}$ are shown in Fig. 4. Due to the different driving torque acted upon the driven shaft before and after the speed synchronization of the driving and driven sides, the current curves show an obvious two different accelerating phases. The armature current has risen to its peak value before the clutch is closed. The equivalent jerk level and per-unit value of current are 10 $\mathrm{m} / \mathrm{s}^{3}$ and 0,25 respectively. The curve of load speed in Fig. 4(a) shows the speed synchronization of the motor and the load is completed before the armature current approaches its peak, i.e, the response curve of the armature current of driving motor is determined by the electromagnetic time constant. The longest engaging time allowing for the rapid clutch engagement is considered to be within (3 4) $\tau_{\mathrm{a}}$ electromagnetic time constant of the driving motor. Therefore, the minimum required terminal value of the armature voltage for meeting the demanded transmitted torque at the clutch closure time is under consideration.

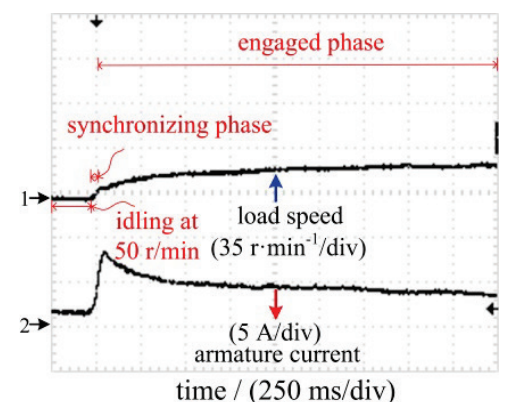

(a)

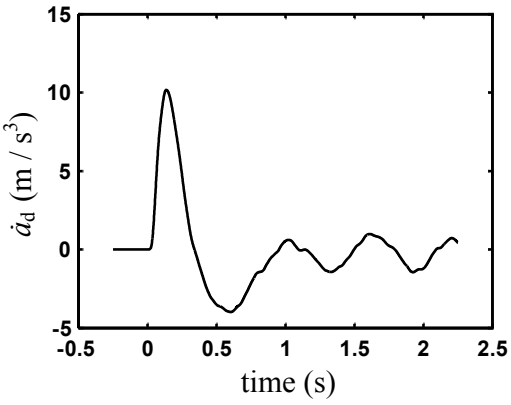

(b)

Figure 4 Scope capture of the clutch start mode idling at the speed of 50 r/min: (a) experimental waveforms of the armature current and the load speed, (b) curves of the equivalent jerk

Then the experiments on different idle speeds under the same load condition mentioned above are performed. Similar to the proportional relations of the idle speed 
versus the transient jerk and the armature current respectively described by Eq. (15) and Eq. (18), the results shown in Fig. 5 indicate that the max jerk value and the armature current both are linearly increased with the rise of the idle speed. The demanded transmitted torque at the clutch closure time can be acquired for assuring the continuous acceleration of the loading motor by the adequate adjustment of idle speed. Also, the results in Fig. 5 also imply that the smaller idle speed will lead to a smaller jerk level, but lower the transmitted torque of the driving motor. Hence, the smaller idle speed to be engaged to the driven side usually results in good driving comfort. However, the negative acceleration of the loading motor will occur when the transmitted torque at the clutch closure time is less than the actual load torque. As shown in Fig. 6, the load speed is gradually decreased to zero after the clutch engagement when the driving motor idling at the speed of $22 \mathrm{r} / \mathrm{min}$ before being engaged to the driven side under the same load condition. Due to the restriction of the idle speed to be engaged to the loading motor for preserving the comfort level, therefore, the track of the armature voltage is adjusted at the right moment while the clutch is engaged to the driven side for improving the performance index further.

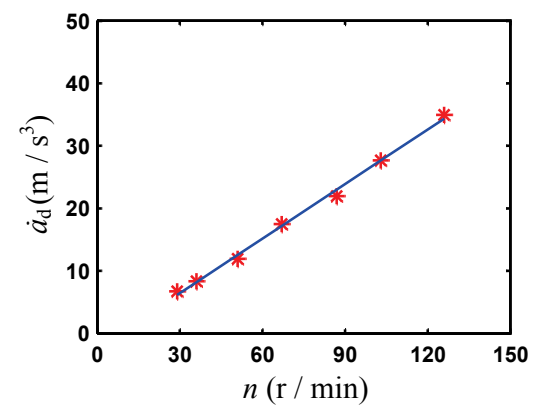

(a)

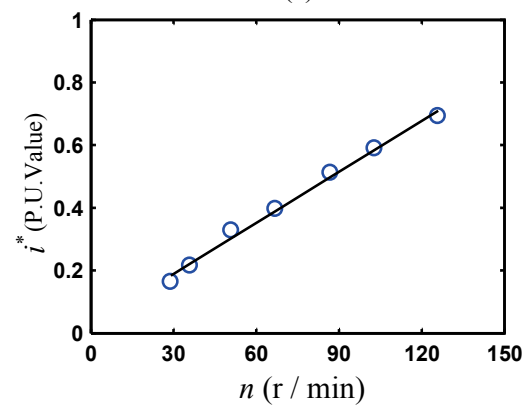

(b)

Figure 5 (a) Relation between the idle speed and the equivalent jerk, (b) Relation between the idle speed and the peak current

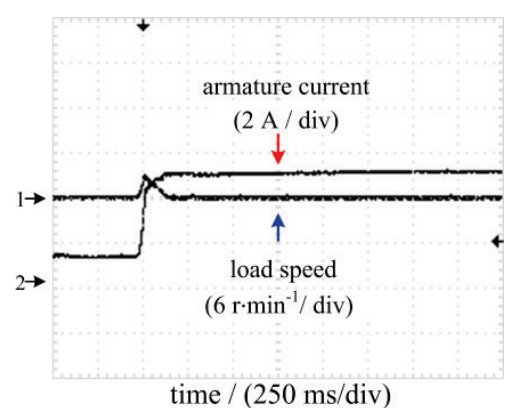

Figure 6 Experimental curves of the armature current and the angular speed of the load when the clutch is engaged to the driven side at a speed of $22 \mathrm{r} / \mathrm{min}$
In the existing experimental conditions, under which the relative jerk level is considered instead of the absolute one. Additionally, because of the linear relationships of the idle speed versus the transmitted torque and the equivalent jerk level, so the engaging speed at the speed of $22 \mathrm{r} / \mathrm{min}$, that is incapable of accelerating the wheel load after clutch engagement, is regarded as the reference idle speed limit, under which the proposed scheme of the armature voltage adjustment and its optimal strategy are investigated. Then the transverse comparisons for performance indices are made between the idle speed control with or without voltage adjustment.

Fig. 7 shows the plotted curves of the terminal value of the armature voltage versus the equivalent jerk level and the peak current. As seen in Fig. 7(b), there is no clear inflection point when the transmitted torque at the clutch closure time is in the vicinity of the load torque, because of the small deceleration of the load after clutch engagement. But, the given terminal value of the armature voltage about $7 \mathrm{~V}$ can be interpreted as a Pareto-optimal point of the two performance indices: for an increasing value of $U_{\mathrm{g}}$, the equivalent jerk is optimal, because the non-obvious improvement for the comfort level by increasing the armature current.

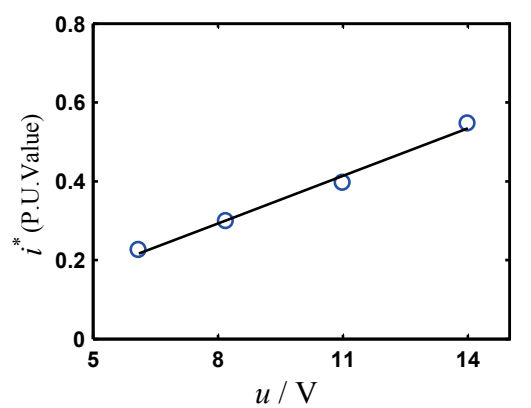

(a)

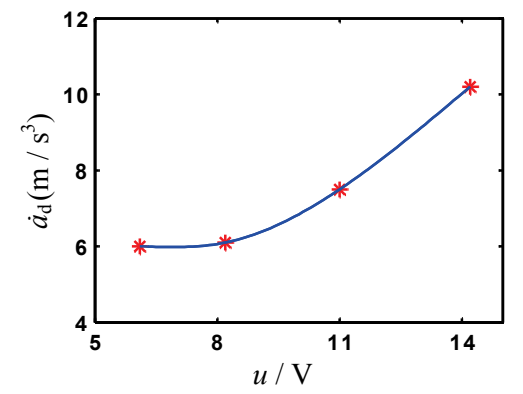

(b)

Figure 7 Relations of the terminal value of armature voltage versus the armature current and the equivalent jerk: (a) plotted curve of the peak current versus the terminal value of armature voltage, (b) plotted curve of the equivalent jerk level versus the terminal value of armature voltage.

Subsequently, the comparisons between the clutch start-up with or without pedal throttle are demonstrated in Fig. 8. Fig. 8(a) shows that the continuous acceleration of the load is acquired after the clutch is fully engaged even under the reference idle speed limit while the terminal of the armature voltage is increased lineally from the initial value of $4 \mathrm{~V}$ to $7 \mathrm{~V}$ during the engagement process. Compared to the clutch start mode with the same terminal voltage, a faster accelerating process is obtained by the idle speed control without armature voltage adjustment. Due to the same terminal armature voltage, the steadystate load speeds in Fig. 8(a) are identical, and the per unit 
value of the peak current is slightly lower than the one without voltage adjustment because of the smaller idle speed to be engaged to the driven side as shown in Fig. 8(b). The result indicates that max value of the equivalent jerk is less than $6 \mathrm{~m} / \mathrm{s}^{3}$, compared with the jerk value of $10 \mathrm{~m} / \mathrm{s}^{3}$ using the clutch start-up without armature adjustment in Fig. 8(c). Moreover, the reduced jerk level is achieved. It suggests the enough transmitted torque can be obtained although the idle speed is confined to the reference restricted value at the speed of $22 \mathrm{r} / \mathrm{min}$. It is implied that a good coordination between the driving comfort and the starting current is assured by the proposed method. Overall, the transverse experimental results on the existing test rig verify the effectiveness of the improvement of torque capacity on the premise of the comfort level.

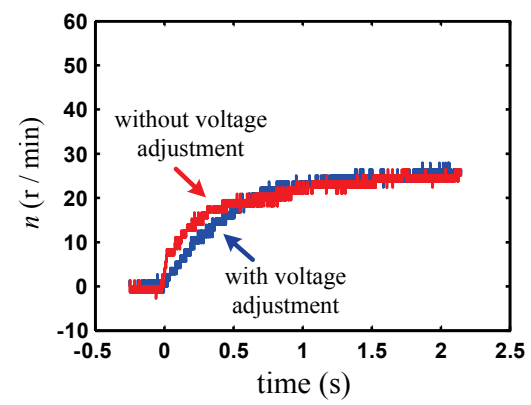

(a)

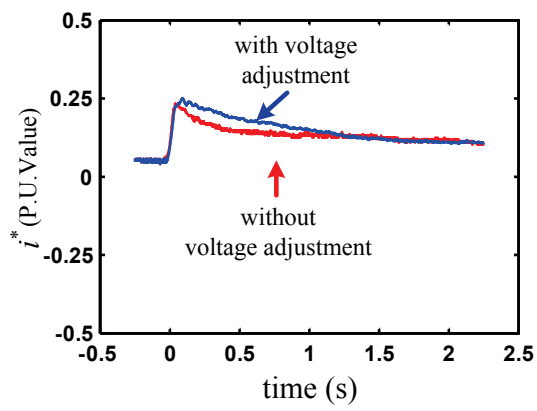

(b)

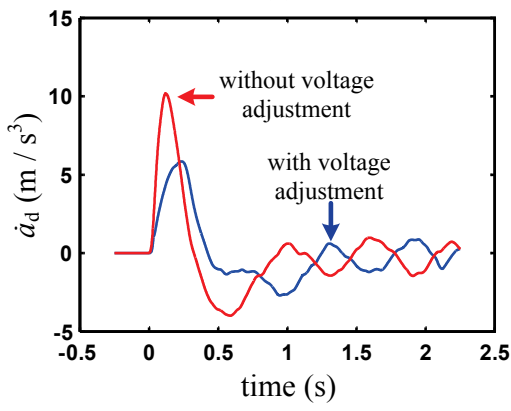

(c)

Figure 8 Comparisons of the armature current, the load speed and the equivalent jerk between the clutch start mode with or without armature voltage adjustment: (a) load speed, (b) current, (c) equivalent jerk

\section{Conclusion}

In order to further improve the torque capacity of the driving motor when the idle speed is limited to a certain rang for preserving the driving comfort, the scheme of automatic adjustment for accelerator pedal while the clutch is engaged to the load is proposed. According to the actual load torque, the track of pedal throttle is correspondingly adjusted. Experimental results indicate the transmitted torque at the clutch closure time is improved without inducing any more starting jerk even though the idle speed is limited to the upper limit value, compared to the starting process by merely increasing the idle speed to keep up with the increase of the load torque. The engagement time and starting intention as the influencing factors are not taken into account. Thus the closed form of on-line adjustment of pedal control would be added to the control strategy to further improve the starting performance of the proposed method in future work.

\section{Acknowledgements}

This work was supported by The National Natural Science Foundation of China (51377063).

\section{References}

[1] Rahman, K. M.; Patel, N. R.; Ward, T. G.; Nagashima, J. M.; Caricchi, F.; Crescimbini, F. Application of DirectDrive Wheel Motor for Fuel Cell Electric and Hybrid Electric Vehicle Propulsion System. // IEEE Transactions on Industry Applications. 42, 5(2006), pp. 1185-1192. https://doi.org/10.1109/TIA.2006.880886

[2] Patterson, D.; Spee, R. The design and development of an axial flux permanent magnet brushless DC motor for wheel drive in a solar powered vehicle. // IEEE Transactions on Industry Applications. 31, 5(1995), pp. 1054-1061. https://doi.org/10.1109/28.464519

[3] Wen, H.; Xiao, W.; Li, H.; Wen, X. Analysis and minimisation of DC bus surge voltage for electric vehicle applications. // IET Electrical Systems in Transportation. 2, 2(2012),pp.66-76. https://doi.org/10.1049/iet-est.2011.0035

[4] Minh, V. T.; Rashid, A. A. Automatic control of clutches and simulations for parallel hybrid vehicles. // International Journal of Automotive Technology. 13, 4(2012), pp. 645651. https://doi.org/10.1007/s12239-012-0063-y

[5] Tan, L. X.; Ning, L. W.; Zhou, Z. R. Controlled by computer's centrifugal clutch to add power with hydraulic pressure and electromagnetism. // Chinese Journal of Mechanical Engineering. 39, 12(2003), pp. 151-153, 157. https://doi.org/10.3901/JME.2003.12.151

[6] Müller, I. N.; Strauss, D. I. F. S.; Tumback, D. I. S.; Christ, I. A. Coasting-Next Generation Start/Stop Systems. // MTZ worldwide eMagazine. 72, 9(2011), pp. 14-19. https://doi.org/10.1365/s38313-011-0084-3

[7] Cai, W. L.; Gu, C. L.; Hu, X. D. Analysis and design of a permanent magnet bi-stable electro-magnetic clutch unit for in-wheel electric vehicle drives. // Energies. 8, 6(2015), pp. 5598-5612. https://doi.org/10.3390/en8065598

[8] Liu, W. X. Vehicle Design. 2nd ed. Tsinghua University Press, Beijing, China, 2000. pp. 72-74.

[9] Baumann, J.; Torkzadeh, D. D.; Ramstein, A.; Kiencke, U.; Schlegl, T. Model-based predictive anti-jerk control. // Control Engineering Practice. 14, 3(2006), pp. 259-266. https://doi.org/10.1016/j.conengprac.2005.03.026

[10] Xiong, P.; Gu, C. L. Optimal idling speed control of directdrive electric vehicle launch in consideration of drive comfort. // In Proceedings of the 17th International Conference on Electrical Machines and Systems / Hangzhou, 2014, pp. 225-228. https://doi.org/10.1109/ICEMS.2014.7013468

[11] Hersey, M. D.; Golden, P. L. Rolling Friction, IVAdditional Car Wheel Experiments. // J Lubric Technol Trans ASME. 92, 1(1970), pp. 83-88. https://doi.org/10.1115/1.3451352

[12] Manfred, M.; Henning, W. Dynamik der kraftfahrzeuge. 1rd ed. Springer, Berlin, Germany, 1972, pp. 15-17. 
[13] Ray, L. E. Estimation of terrain forces and parameters for rigid-wheeled vehicles. // IEEE Transactions on Robotics. 25, 3(2009), pp. 717-726. https://doi.org/10.1109/TRO.2009.2018971

[14] Domenech, A.; Domenech, T.; Cebrian, J. Introduction to the study of rolling friction. // American Journal of Physics. 55, 3(1987), pp. 231-235. https://doi.org/10.1119/1.15223

[15] Kember, S. A.; Powell, N. N.; Poggi, M.; Ellis, D.; Sung, J. Modelling of snap start behaviour in an automotive driveline. // (MSCSCsoftware support libary, 1999).

[16] Fujii, Y.; Ohgushi, K.; Tojo, T. A proposal for a dynamicresponse-evaluation method for torque transducers. // Measurement Science \& Technology. 10, 12(1999), pp. 142-144. https://doi.org/10.1088/0957-0233/10/12/403

[17] Mosterman, P. J.; Biswas, G.; Otter, M. Simulation of discontinuities in physical system models based on conservation principles. // Proceedings of the Summer Computer Simulation Conference / Reno, 1998, pp. 320325

[18] Maurice, J. P.; Savkoor, A. R. Influence of flexibility properties and friction laws on tyre behaviour. // Vehicle System Dynamics, 37, suppl.issue. (2003), pp. 107-124.

[19] Huang, Q. N.; Wang, H. Y. Fundamental study of jerk: Evaluation of shift quality and ride comfort. // SAE Automotive Dynamics, Stability and Controls Conference and Exhibition / Detroit, 2004, pp. 93-98. https://doi.org/10.4271/2004-01-2065

[20] Gao, B. Z.; Chen, H.; Lu, X. H.; Sanada, K. Improved optimal controller for start-up of AMT trucks in consideration of driver's intention. // International Journal of Automotive Technology. 14, 2(2013), pp. 213-220. https://doi.org/10.1007/s12239-013-0024-0

[21] Bóka, G.; Márialigeti, J.; Lovas, L.; Trencséni, B. Face dog clutch engagement at low mismatch speed. // Periodica Polytechnica Transportation Engineering. 38, 1(2010), pp. 29-35. https://doi.org/10.3311/pp.tr.2010-1.06

[22] Famouri, P.; Cooley, W. L. Design of DC traction motor drives for high efficiency under accelerating conditions. // IEEE Transactions on Industry Applications. 30, 4(1994), pp. 1134-1138. https://doi.org/10.1109/28.297932

[23] Duan, C. W.; Jhou, H. L.; Ma, B. Y.; Shyu, K. K. Analytical Study of a Dog Clutch in Automatic Transmission Application. // SAE International Journal of Passenger Cars - Mechanical Systems. 7, 3(2014), pp. 1155-1162. https://doi.org/10.4271/2014-01-1775

[24] He, H. W.; Liu, Z. T.; Zhu, L. M.; Liu, X. L. Dynamic coordinated shifting control of automated mechanical transmissions without a clutch in a plug-in hybrid electric vehicle. // Energies, 5, 8(2012), pp. 3094-3109. https://doi.org/10.3390/en5083094

[25] Garofalo, F.; Glielmo, L.; Iannelli, L.; Vasca, F. Smooth engagement for automotive dry clutch. // Proceedings of the 40th IEEE Conference on Decision and Control / Orlando, 2001, pp. 529-534. https://doi.org/10.1109/CDC.2001.980156

[26] Kolar, J. W.; Biela, J.; Miniböck, J. Exploring the Pareto front of multi-objective single-phase PFC rectifier design optimization - $99.2 \%$ Efficiency vs. $7 \mathrm{~kW} / \mathrm{dm} 3$ power density. // Design Methods for Performance and Sustainability, Proceedings of the 2009 IEEE 6th International Power Electronics and Motion Control Conference / Wuhan, 2009, pp. 1-21 https://doi.org/10.1109/IPEMC.2009.5289336

\section{Authors' addresses}

Xiong Ping, working towards the PhD

State Key Laboratory of Advanced Electromagnetic Engineering and Technology, Huazhong University of Science \& Technology, Room 6107, Dianjilou, Luoyu road, Wuhan, P. R. China

E-mail:px_joey@163.com

\section{Gu Chenglin, Professor}

State Key Laboratory of Advanced Electromagnetic Engineering and Technology, Huazhong University of Science \& Technology, Wuhan 430074, P. R. China

E-mail: clgu@mail.hust.edu.cn 